\title{
O Programa Mais Educação e a indução da educação integral: desafios para o currículo escolar
}

Áurea Andrezza Silva dos Santos*

Ney Cristina Monteiro de Oliveira**

*Mestre em Educação pela Universidade Federal do Pará

Especialista em Educação Seduc-PA

E-mail:

aureassantos@yahoo.com.br

**Doutora em Educação pela Pontifícia Universidade Católica de São Paulo

Professora de Graduação do Curso de Pedagogia e do Programa de Pós-Graduação da Universidade Federal do Pará

E-mail:neycmo@ufpa.br
Resumo: Este texto trata de um recorte de parte da dissertação de mestrado que manifesta a precariedade que afeta a qualidade do ensino público brasileiro. Assim, o poder público cria o Plano de Desenvolvimento da Educação (PDE) em 2007, composto de inúmeras ações para a melhoria dessa qualidade, focando principalmente a educação básica. Dentre as ações desse plano de governo, selecionamos o Programa Mais Educação (PME), cuja meta é a retomada da educação integral nas escolas públicas brasileiras, oportunizando aos seus alunos a ampliação do tempo escolar, de espaços e de outras oportunidades educativas para atingir a formação do cidadão pleno e integral. Logo, entendemos a relevância do currículo para a implantação da concepção de educação integral e para a escola de tempo integral.

Palavras-chave: Política educacional. Educação integral. Programa Mais Educação. Currículo. 


\section{INTRODUÇÃO}

A concepção de educação integral é um anseio desde a década de 1920. Está descrita implicitamente no Manifesto dos Pioneiros de 1932, que teve o apoio de Anísio Teixeira e de outros educadores, explicitando a relevância, naquele momento histórico, de renovar a educação brasileira, adotando um modelo de educação que não fosse excludente e buscasse a formação integral do sujeito por meio da vinculação do trabalho escolar com o meio social a que 0 sujeito pertence (GODOY, 2012).

Novamente, no século XXI, o debate sobre a educação integral é retomado para melhorar a educação brasileira procurando desenvolver integral e plenamente o sujeito através de outros componentes curriculares, com a ampliação da jornada escolar e a utilização de outros espaços educativos.

Entendemos que, nessa concepção de educação, o sujeito é integral, não é um ser fragmentado. Portanto, na perspectiva de compreensão do homem, trata-se de um ser multidimensional, sendo que a educação deve responder a uma multiplicidade de exigências do próprio indivíduo e do contexto em que vive, de modo que a educação ofertada, bem como o currículo, deverá atender a essas expectativas. Assim, a educação integral deve ter objetivos que construam relações na direção do aperfeiçoamento humano para a formação do cidadão.

O país carece de uma escola que oferte escolarização para além dos muros da escola, que tenha uma jornada escolar ampliada, ofertando inúmeras atividades de cultura, esporte, lazer, cidadania, além daquelas que atendem ao currículo oficial. Essas atividades se materializam atualmente por meio do Programa Mais Educação (PME), que impulsiona a realização da política de educação integral e busca essa ampliação com a construção da oferta da concepção de educação integral. O programa amplia o tempo diário dos alunos nas escolas públicas brasileiras, renovando a oferta de educação pública, pois o objetivo da escola pública é ofertar aprendizagem de qualidade, garantir que o aluno tenha acesso a conceitos e pressupostos fundamentais, invertendo a lógica da dominação, oriunda da sociedade capitalista, que domina a aquisição de conhecimentos, cultura e novas competências e habilidades, assim oportunizando que "filhos dos trabalhadores e das camadas pobres e médias tenham, definitivamente, os mesmos direitos à cultura, ao conhecimento e ao saber" (CARLINI, 2012, p. 444).

Para atingir essa qualidade, há muitos desafios a serem superados. Para Moll 
(2012), um dos grandes desafios é a escola dividida por turnos. A educação integral, dentro de uma escola de tempo integral, busca superar "minguadas quatro horas diárias que caracterizam na escola de turno" (MOLL, 2012, p. 28).

No governo do presidente Lula (2002-2010), foi criado um plano educacional para socorrer a agonizante educação pública brasileira. Em 2007, o Ministério de Educação (MEC) lançou o Plano de Desenvolvimento da Educação (PDE), que se propôs a melhorar a qualidade do ensino público brasileiro. O PDE constituiu-se inicialmente de 28 ações que, posteriormente, avançaram para 51 ações a ser cumpridas pelos municípios e estados para melhorar a qualidade da educação no país. O PDE apontou múltiplas ações em todos os níveis e modalidades de educação, mais especificamente a educação básica, com número maior de ações voltadas para o ensino fundamental. Gadotti (2008) ressalta que o PDE tem grandes possibilidades de dar certo, pois seu principal foco é a qualidade da aprendizagem da educação brasileira.

Dentre as ações deste plano, nosso estudo selecionou aquela que tem como meta o princípio da oferta da educação integral, que se expressou por meio do PME, que tem como proposta ampliar a jornada escolar na perspectiva desta educação, aumentando as possibilidades educativas por meio de diversas atividades culturais, esportivas, sociais, ambientais, tecnológicas, o que permitirá ao aluno da escola pública a apropriação do capital cultural ${ }^{1}$. Todavia, tal processo não é simples, pois solicita repensar os componentes pedagógicos da escola, dentre eles o currículo, para que se possam ofertar diversas atividades propostas pelo PME.

\section{Percurso metodológico}

Para entender esse campo conflituoso de realização das políticas públicas educacionais que é a escola, utilizamos a abordagem qualitativa, pois, para Gamboa e Santos (2009, p. 43), a pesquisa qualitativa "está mais preocupada com a compreensão (verstehen) ou interpretação do fenômeno social [...]. 0

\footnotetext{
Segundo Menezes (2009), emprestado da economia, o termo capital cultural tem um papel nodal para o pensamento sociológico de Pierre Bourdieu, cujos estudos acentuaram a dimensão de que a origem social dos alunos se constitui em desigualdades escolares. Em outras palavras, o capital cultural é o que pode designar o sucesso ou o fracasso de cada aluno. Afinal, algumas evidências apontam que as limitações do conceito de capital econômico explicam a ligação entre o nível socioeconômico e os bons resultados educacionais. Isso nos faz considerar que outras formas de capital, como o social e o cultural, contribuem diretamente e interagem com o capital econômico para fortalecer as relações sociais.
} 
pesquisador precisa tentar compreender o significado que os outros dão às suas próprias situações”.

Fizemos uma análise bibliográfica da literatura existente sobre educação integral e o PME, bem como sobre a formação de professores nas produções do meio acadêmico e entre autores que tratam da temática, com o objetivo de depreender como a produção acadêmica brasileira vem abordando tal temática. 0 corpus dessa análise irá abranger livros, artigos, periódicos do período do Manifesto dos Pioneiros, de 1932, até a contemporaneidade.

A análise bibliográfica tem por objetivo analisar as literaturas que estão sendo utilizadas em trabalhos que abrangem a temática da educação integral, bem como das políticas públicas. Segundo Severino (2007, p. 122), “utiliza-se de dados ou de categorias teóricas já trabalhados por outros pesquisadores e devidamente registrados. Os textos tornam-se fonte do tema a serem pesquisados".

Foi realizada também a análise documental, que se caracteriza como uma fonte de coleta de dados restrita a documentos, escritos ou não, constituindo o que se denomina fontes primárias (LAKATOS; MARCONI, 1991). Para ter acesso às informações que norteiam as políticas públicas educacionais da educação integral, bem como o PME, analisamos os seguintes documentos: PDE; Decreto no 6.094, de 24 de abril de 1997 (Plano de Metas Compromissos Todos pela Educação); Portaria Interministerial 17/2007 e o Decreto Presidencial 70832010, que institui legalmente o PME e o integra ao PDE.

\section{A EDUCAÇÃO INTEGRAL E O PME: ANTIGOS HORIZONTES PARA A NOVA EDUCAÇÃO PÚBLICA DE QUALIDADE}

Há vários conceitos divergentes quando se trata de educação integral. Contudo, eles convergem ao entender que o ser humano deve ser visto em sua totalidade, não sintetizando apenas a questão cognitiva, mas mencionando com mesma importância as dimensões corporal, social, afetiva, cultural, entre outras, que constituem o ser humano integral. Nessa perspectiva, a escola se articulará mais com a comunidade local culminando em projetos que contribuam para a formação integral do sujeito. 
Apreendendo a relevância dessa formação do sujeito como ser integral tão aclamado pelo Manifesto dos Pioneiros em $1932^{2}$, lançou-se mais um plano, o PDE, com o intuito de recuperar a educação brasileira do caos já implantado e enraizado há muitos anos em nosso país. Ao mesmo tempo do lançamento do PDE tivemos a promulgação do Decreto no 6.094, dispondo sobre o "Plano de Metas Compromisso Todos pela Educação" 2008). No $2^{\circ}$ artigo do Plano de Metas Compromisso Todos pela Educação está traçado o interesse para a ampliação do tempo escolar como uma das formas de combater a repetência e a recuperação e progressão parcial.

O PME tem a finalidade de universalizar a educação integral nas escolas públicas brasileiras. Assim, a política de educação integral construiu-se baseada na análise dos baixos índices de aprendizagem da escola pública atestados pelo Índice de Desenvolvimento da Educação Básica (Ideb), que avalia a qualidade do ensino da educação básica. O Programa é instituído pela Portaria Interministerial ${ }^{4}$ 17/2007 e pelo Decreto Presidencial 7083/2010, integrando as ações do PDE como tática do governo federal para levar à ampliação da jornada escolar e à organização curricular, na perspectiva da educação integral (BRASIL, 2007).

Conforme Gadotti (2008, p. 68), o que se pretende com as articulações dos ministérios “é construir uma política de Estado, não uma política de governo". Percebemos assim que o PME traz uma forte e consolidada articulação entre as áreas da educação, cultura, esporte e assistência social, e que esta articulação promove a proteção social, buscando a possível melhoria no desempenho escolar de crianças e adolescentes. Isso fica ratificado no

2 Para Santos (2013), o Manifesto dos Pioneiros de 1932 consistia no documento que ambicionava pela reconstrução educacional brasileira, que elegia a escola pública, laica, gratuita como dever do Estado. Disseminava que "a educação deve ser universal, isto é, tem de ser organizada e ampliada de maneira que seja possível ministrá-la a todos sem distinções de qualquer ordem; obrigatória e gratuita em todos os graus; integral, no sentido de que, destinando-se a contribuir para a formação da personalidade da criança, do adolescente e do jovem, deve assegurar a todos o maior desenvolvimento de suas capacidades físicas, morais, intelectuais e artísticas (AZEVEDO, 1932, p. 90)”.

3 Instituído pelo decreto 6.094/2007, o plano tem por objetivo conjugar os esforços de União, estados e municípios e família para desenvolverem as diretrizes em suas redes de escolas e nas práticas pedagógicas respeitando as metas do Ideb para assegurar a qualidade da educação básica.

4 A Portaria Interministerial 17/2007 (BRASIL, 2007) consiste no empenho de vários ministérios como o Ministério da Educação, Ministério da Cultura, Ministério do Esporte, Ministério do Meio Ambiente, Ministério do Desenvolvimento Social e Combate à Fome, Ministério da Ciência e Tecnologia, para ser desenvolvida a concepção de educação integral por meio da ampliação de tempos e espaços. 
parágrafo único do $1^{0}$ artigo da Portaria Interministerial 17/2007:

O programa será implementado por meio do apoio à realização, em escolas e outros espaços socioculturais, de ações socioeducativas no contraturno escolar, incluindo os campos da educação, artes, cultura, esporte, lazer, mobilizando-os para a melhoria do desempenho educacional, ao cultivo de relações entre professores, alunos e suas comunidades, à garantia da proteção social da assistência social e à formação para a cidadania, incluindo perspectivas temáticas dos direitos humanos, consciência ambiental, novas tecnologias, comunicação social, saúde e consciência corporal, segurança alimentar e nutricional, convivência e democracia, compartilhamento comunitário e dinâmicas de redes (BRASIL, Portaria Interministerial 17/2007).

Ainda no Decreto Presidencial 7083/2010 (BRASIL, 2010), os objetivos do PME exibidos no 30 artigo são:

I- formular política educacional de educação básica em tempo integral;

II- promover diálogo entre os conteúdos escolares e o saberes locais;

III- favorecer a convivência entre professores, alunos e suas comunidades;

IV- disseminar as experiências das escolas que desenvolvem atividades de educação integral.

Percebemos no decreto acima a valorização dos saberes entre escola e a comunidade local e a menção dos termos educação integral e tempo integral. A temática educação integral é atrelada à escola de tempo integral e a inúmeras e diversas iniciativas de implantação de rica importância que preencheram o contexto educacional brasileiro. O que notamos é que as escolas que se denominam de tempo integral ainda caminham para ofertar o que hoje se entende como concepção de educação integral, pois apenas realizam extensão de atividades esportivas, artísticas e/ou culturais sem relação com o currículo escolar que é necessário para o desenvolvimento da educação integral. Essas atividades compõem uma das finalidades do PME conforme 0 $2^{\circ}$ artigo, inciso VI, da Portaria Interministerial 17/2007 (BRASIL, 2007), que deverá atender todos os alunos por meio de esporte, lazer e educação, o que contribuirá para o desenvolvimento humano desses alunos.

A educação integral possui campo fértil no Brasil neste século XXI, não somente na área educacional, pois se propõe ao desafio de guerrear contra um grande problema que assola milhões de crianças e adolescentes brasileiros: a vulnerabilidade social que fortalece a pobreza e as desigualdades sociais. A escola possui papel fundamental para enfrentar esse problema, pois ela "representa praticamente a única presença do Estado na vida dessas comunidades" (COSTA, 2012, p. 478). Contudo, ao mesmo tempo a escola 
apresenta o descaso do Estado com este espaço, visível na oferta de uma educação pública de pouca qualidade, além da má infraestrutura física dos prédios, baixos salários dos profissionais da educação e descontinuidade das políticas públicas educacionais.

Todavia, esses não são os únicos possíveis problemas para o desenvolvimento da educação integral. Atuar por meio da concepção de educação integral é repensar e articular principalmente duas variáveis: tempo e espaço.

Tempo no que se refere à sua ampliação durante a jornada escolar. Não se trata apenas de aumentar o tempo para se ofertar mais do mesmo. É aumentar as possibilidades de diferentes práticas educativas e não se deter somente na questão de melhorar os déficits educacionais. Isso apenas será consequência de um processo que almeja como resultado principal uma nova postura para nossos alunos, seja na aprendizagem, seja nas experiências de vida. Conforme Cavalieri (2007, p. 100),

Torna-se então necessário abordar a questão do tempo de escola de forma a ir além da tentativa de resolver os déficits da escola pública brasileira, nos moldes em que hoje ela se estrutura. Um passo inicial parece ser a análise do tempo de escola em sua dimensão sociológica, ou seja, na dimensão que o compreende como tempo social.

Entendemos que aumentar o tempo sem um direcionamento e proposição de que ampliar é necessário dentro de uma reorganização pedagógica na escola não solucionará antigos problemas educacionais.

O espaço se refere ao território que a escola pertence e aos territórios que ela influencia, o que permitirá um precioso diálogo com a comunidade local, regional e global. Essa articulação deverá ter como culminância uma organização do currículo, com o aumento das disciplinas e com a incorporação de novos espaços, como parques recreativos, laboratórios e auditórios.

Assim, "é preciso mirar os espaços das escolas e também os de fora delas com outros olhos, potencializar seu uso, refletir acerca de qual infraestrutura é adequada para a ampliação da jornada e quais são os arranjos possíveis a serem feitos" (LOMONACO; SILVA, 2013, p. 20).

A questão de tempo e espaço ampliados, bem como a organização de um currículo que vise à formação integral do aluno, é elucidada no 6ำ artigo, inciso I, da Portaria Interministerial 17/2007 (BRASIL, 2007), que é “contemplar a ampliação do tempo e do espaço educativo de suas redes e escolas, pautada pela formação de proteção integral e emancipadora". 
A educação integral já foi proposta como política de governo no Brasil, ligada estritamente à responsabilidade dos sistemas de ensino. Assim, foram propostas e implementadas escolas de tempo integral, como as escolasparque em 1954, desenvolvidas por Anísio Teixeira na Bahia, os Centros Integrados de Educação Pública (Ciep), em 1986, e os Centros Integrados de Apoio à Criança (Ciac), em 1990.

Em 2008, o PME chegou até a rede pública de ensino estadual do Pará, onde se levou em consideração também a regionalização no processo de aprendizagem. Foi o que podemos perceber nas experiências educacionais realizadas no município de Santarém, que ampliou tempos e espaços para as atividades estimando o contexto regional amazônico a partir do momento da valorização dos saberes dos povos dos rios e florestas e a integração dos mesmos com os saberes dos povos da cidade, ou seja, é a cultura local e o seu jeito de viver sendo difundidos e contribuindo para a formação da cidadania dos alunos, além de contribuir para a reflexão da prática pedagógica dos educadores (PINHEIRO; RODRIGUES, 2012). Notamos, na experiência do município de Santarém, como a educação integral pode contribuir na relação do espaço escolar com a comunidade local e no fortalecimento da regionalização daquele local.

Para participar do PME, a escola pública precisa preencher e enviar à Secretaria de Educação Estadual o termo de adesão e compromisso e, posteriormente, preencher no Sistema Integrado do Ministério da Educação (Simec) seu plano de atividades e alunos atendidos.

A Secretaria de Educação Continuada, Alfabetização e Diversidade (Secad), em parceria com a Secretaria de Educação Básica (SEB), são as responsáveis por operacionalizar o PME tendo como executor financeiro o Fundo Nacional de Desenvolvimento da Educação (FNDE), que por meio do PDDE distribui os recursos financeiros para as escolas para a execução do PME, financiando o material das atividades, bem como o ressarcimento do trabalho efetuado pelo monitor que as desenvolve. Assim, os macrocampos e suas atividades são escolhidos pela direção da escola para funcionarem no contraturno, segundo o MEC.

Segundo Santos (2013), em março de 2013, o PME passou por um redesenho, buscando responder ao desafio de superar a dicotomia entre turno e contraturno, de modo que as atividades escolhidas sejam incorporadas nas práticas cotidianas dos professores e professoras, integrando o trabalho de monitores e professores. Portanto, segundo o MEC, o PME possibilita uma ação 
específica para jovens de 15 a 17 anos que ainda estão no ensino fundamental. O objetivo é proporcionar a esses estudantes um espaço educativo para aprendizagens e convivência e assegurar sua permanência para a conclusão com qualidade do ensino fundamental. O PME também atenderá os alunos a partir de 6 anos com atividade de alfabetização e letramento. Logo, as atividades foram reorganizadas em sete macrocampos (BRASIL, 2013):

- Acompanhamento Pedagógico: Orientação de estudos e leitura: alfabetização e letramento, Ciências, História e Geografia, Línguas Estrangeiras, Matemática, Língua Portuguesa, com ênfase em leitura e produção de texto.

- Educação Ambiental e Sociedade Sustentável: Horta escolar e/ ou comunitária, jardinagem escolar econômica solidária e criativa, educação econômica.

- Esporte e Lazer: Badminton, luta olímpica, vôlei de praia, atletismo, basquete de rua, basquete, corrida de orientação, futebol, futsal, ginástica rítmica, handebol, judô, caratê, natação, recreação e lazer/ brinquedoteca, taekwondo, tênis de campo, tênis de mesa, voleibol, xadrez tradicional, xadrez virtual, ioga/meditação.

- Educação em Direitos Humanos: Educação em direitos humanos, tecnologias educacionais.

- Cultura, Artes e Educação Patrimonial: Artesanato popular, banda fanfarra, canto coral, capoeira, cineclube, danças, desenho, educação patrimonial, ensino coletivo de cordas, escultura, iniciação musical por meio da flauta doce, grafite, hip-hop, leitura e produção textual, mosaico, percussão, pintura, práticas circenses, teatro, tecnologias educacionais.

- Promoção da Saúde: Promoção da saúde e prevenção de doenças e agravos, tecnologias educacionais.

- Comunicação, Uso de Mídias, Cultura Digital e Tecnológica: Ambientes de redes sociais, fotografia, histórias em quadrinhos, jornal escolar, rádio escolar, vídeo, robótica educacional.

O público-alvo do PME na escola é uma pequena parcela de alunos: apenas os considerados em situação de risco e, além disso, que possuam problemas de aprendizagem e defasagem de idade. Verificamos que o programa não é visto como um direito de todos os alunos da escola, fortalecendo o processo excludente. Contudo, cada escola implementa o PME de acordo com sua realidade. As turmas deverão ser formadas com, no mínimo, 20 alunos e, no máximo, 30 alunos, podendo haver sempre que possível a mescla de alunos de diferentes idades e séries. As atividades do PME são coordenadas por 
um professor da escola e desenvolvidas por monitores que são estudantes universitários com formação específica nas áreas de desenvolvimento, educadores populares e agentes culturais, como estudantes da Educação de Jovens e Adultos (EJA) e do ensino médio, que serão os responsáveis por conduzir os macrocampos. Esse trabalho realizado deverá ser considerado de natureza voluntária na forma definida pela Lei no 9.608 de 18 de fevereiro de 1998, logo o valor do ressarcimento é de acordo com o número de turmas formadas, que varia de $\mathrm{R} \$ 80,00$ (uma turma) a $\mathrm{R} \$ 400,00$ (cinco turmas), custeando despesas com alimentação e transporte, mensalmente.

As atividades e o custeio do material necessário são financiados, de acordo com o número de estudantes atendidos pelo PME, conforme a tabela abaixo:

Tabela 1 - Valor do repasse financeiro de acordo com a quantidade de estudantes inscritos no Programa Mais Educação

\begin{tabular}{l|l|l} 
Quantidade de estudantes & Recursos mensais - RS & Total (RȘ) \\
Até 500 estudantes & 500,00 & $5.000,00$ \\
\hline De 501 a 1.000 estudantes & $1.000,00$ & $10.000,00$ \\
\hline Mais de 1.001 estudantes & $1.500,00$ & $15.000,00$ \\
\hline Fonte: BRASIL, 2010.
\end{tabular}

Verificamos, pela Tabela 1 , que o recurso financeiro mensal repassado às escolas públicas é insuficiente para a escola desenvolver suas atividades com a qualidade esperada, pois percebemos que para cada aluno o valor repassado por mês é de apenas $R \$ 1,00$ - e $R \$ 10,00$ durante os dez meses do funcionamento do PME, que é investido nas atividades realizadas na escola. Os kits poderão ser adquiridos pelo recurso financeiro enviado às escolas pelo FNDE ou o material que é enviado às escolas também pelo FNDE (BRASIL, 2010).

O valor repassado para as escolas públicas é para o financiamento das atividades dos macrocampos selecionados pelas unidades escolares, por um período de dez meses, não havendo outro recurso financeiro para a substituição de material desgastado. Sobre a alimentação, ela é garantida ao aluno que permanecer por mais tempo na escola. Contudo, refere-se a envio de gêneros alimentícios às Unidades Executoras, não deixando clara a oferta de almoço por parte do PME (BRASIL, 2010). 
CURRÍCUlo e CONTEÚdos: O QUE É NECESSÁRIO PARA A CAMINHADA DA EDUCAÇÃO INTEGRAL E DO PME

Retornar ao debate da educação integral e da escola de tempo integral nos faz repensar inúmeros fatores para seu desenvolvimento e possível concretização. Para Santos (2013), a implantação do PME revelou que inúmeras são as dificuldades para o programa se desenvolver no espaço escolar, pois é necessária a reorganização institucional, além de deflagrar a fragilidade de alguns componentes pedagógicos - dentre eles, destacamos a questão curricular.

Inovações nos remetem a possíveis mudanças conjunturais, o que não seria diferente em relação ao currículo, que deverá se apoiar na concepção de educação integral e em uma escola de tempo integral que necessita de formação continuada para os professores. Estes devem refletir sobre a prática docente que envolverá a organização do currículo escolar com o objetivo de integrar os conhecimentos curriculares à realidade social, local e regional do aluno, entendendo que não há um único modo de ensinar e aprender, logo a escola não será o único templo de conhecimento e aprendizagem, o que ocasionaria constante diálogo com a sociedade. 0 que se pretende conquistar é um currículo rico. De acordo com Branco (2012, p. 101):

Na nova proposta de currículo acrescentaram, aos conteúdos tradicionais de Português, Matemática, Ciências, História e Geografia, outros até então considerados menos importantes, como: as artes, a cultura das comunidades locais, os esportes e a preparação para o trabalho. Na organização do tempo escolar, foi criado o turno, destinado às disciplinas tradicionais e o contraturno,

Compreendemos por que o PME oferece como componente curricular macrocampos com inúmeras atividades para a construção de novos conhecimentos. Eis que se apresenta a prática docente como fator fundamental para essa construção.

Para Moll (2010), é imprescindivel a formação para o professor. Este é o primeiro desafio para atuar com educação integral em uma jornada ampliada, pois mais tempo na escola culmina em formar e qualificar educadores para atuarem nessa nova realidade educacional.

O docente terá que entender a organização do seu trabalho dentro deste tempo ampliado, rever planejamento, aprender novas didáticas, conteúdos, metodologias e avaliação. Além disso, é preciso se adaptar aos novos espaços 
educativos que a comunidade local e a cidade oferecem que irão contribuir para a aprendizagem do aluno.

É sobre essa aprendizagem que ressaltamos a discussão sobre o currículo. Que aprendizagens a educação integral e uma escola de tempo integral poderão proporcionar aos seus alunos? É fato que se deverá atentar para as infinitas formas de aprendizagem das atuais gerações. Entender que essa aprendizagem não se baliza apenas nas escolas, que ela perpassa a comunidade local e espaços públicos, que viabilizará o pertencimento ao seu bairro e município.

Segundo Santos (2013), ofertar educação integral não é apenas ampliar a jornada escolar; é instaurar uma concepção de educação que oferte ao aluno competências diferenciadas que o mundo atual exige.

Dessa maneira, o que sêssimetende é oferecer novas oportunidades educativas e proporcionar aos estudantes interações em outros tempos, que não dizem respeito apenas ao tempo cronológico, mas também ao tempo subjetivo da aprendizagem, aquele que considera a individualidade, as interações grupais e os aspectos culturais dos estudantes (LOMONACO; SILVA, 2013, p. 19).

Entendemos que, para esse tempo subjetivo, os componentes pedagógicos precisam ser repensados, e para este estudo iremos nos deter no currículo e na necessidade de que este proporcione conteúdos que possam contribuir e articular conhecimentos que proporcionem aprendizagens significativas para a vida do aluno. Para alcançar essas aprendizagens é necessário que haja um diálogo entre o conhecimento acumulado de geração a geração com a tecnologia da informação gerada pelo mundo moderno, e isso nos faz refletir sobre a necessidade de um novo currículo que efetive esse diálogo. Para Lomonaco e Silva (2013, p. 22):

Faz-se necessário ousar e rever o ensino regular para dar conta de educar uma geração que nasceu na era da informação, da tecnologia e da velocidade. Pensar um novo currículo significa vislumbrar outras maneiras pelas quais a ação educativa possa ser efetivada.

Compreendemos que essas outras maneiras são possíveis devido ao currículo, segundo Apple (2006), não ser neutro, uma vez que o conhecimento ministrado na escola atende a interesses sociais e a políticas educacionais (controle social), o que contribui para a desigualdade social.

Entretanto, para evitar a permanência dessa desigualdade social, segundo Sacristán (1998), é necessário promover a participação de alunos e pais na construção do currículo, que, devido a sua função emancipadora, permite ir contra a lógica do processo de dominação. 
Santos (2013), ao tratar da questão curricular, afirma que o PME poderá auxiliar a amenizar o caráter apenas conteudista que as grades curriculares brasileiras oferecem aos alunos; conteúdos que em alguns casos não possuem significados para a vida dos estudantes, ocasionando desencanto para o aluno e falta de entusiasmo dos professores em construir saberes com seus educandos, uma vez que precisam vencer os milhares de conteúdos que compõem o currículo.

O currículo da concepção de educação integral precisa pelejar para a emancipação do sujeito, pois, de acordo com Cavalieri (2012), essa concepção de educação caminha nesta vertente de emancipação, uma vez que concebe uma escola pública para todos com qualidade sempre articulada com diferentes espaços e sujeitos, uma escola que possa dialogar com os diversos campos do saber, não apenas com conteúdos predeterminados, uma escola que defenda os interesses da tarefa de educar, procurando revolucionar a educação brasileira de modo a ser ofertada com equidade.

Conforme Cavalieri (2012), o que se busca é a integração dos diferentes saberes que constituirá "a espinha dorsal da proposta pedagógica desse Programa" (p. 285). Isso nos reporta ao currículo integrado para alcançar a democratização da educação básica. Sobre o currículo integrado:

O termo "integrado" ao adjetivar currículo expressa o resultado do ato de integrar saberes particulares em um espaço no qual circulam saberes socialmente legitimados para serem ensinados e aprendidos. Envolve a mobilização de critérios de seleção e de organização do conhecimento escolar. Isso significa que ao estabelecer o que pode/deve ser considerado como um saber/conhecimento passivel de ser integrado, o ato de integrar define simultaneamente os sentidos de saber/conhecimento, do jogo político no qual as lutas por essa definição estão sendo travadas, bem como define também o contexto contingencial em que elas ocorrem (CAVALIERI, 2012, p. 286).

Este currículo integrado deflagra uma possibilidade de socializar 0 conhecimento e torná-lo mais democrático, uma vez que permite combater a hierarquização de conhecimentos. Assim, esse currículo busca problematizar as disciplinas na definição das disciplinas escolares. Entende-se que integrar é procurar a articulação entre o conhecimento escolar organizado, por meio de suas matrizes curriculares, e as demandas sociais.

Essa articulação é importante, uma vez que deflagra as características da comunidade que a educação integral pretende integrar, uma comunidade de baixa renda e que possui dificuldade de acesso aos bens culturais. Por isso, um dos objetivos do PME busca, segundo Cavalieri (2012, p. 290), “dar mais aos que têm menos". 
O currículo escolar que atenderá a essa educação integral e será aplicado na escola de tempo integral precisa ter como eixo o entendimento de que esse tipo de educação amplia oportunidades de vida e proporciona aprendizagem significativa e, consequentemente, emancipadora. Entendese que não é ofertar o que já se oferta com o currículo básico; ressaltamos que ele é indispensável, contudo, é preciso ir além, repaginar esse currículo tanto qualitativamente (ressignificação dos conteúdos, um currículo vivo) como quantitativamente (jornada ampliada), para que assim se ofertem aos alunos outras oportunidades educativas. Eis a importância de reorganizar os espaços e tempos da escola, pois se trata de uma transformação necessária na estrutura administrativa e pedagógica da escola.

O que se pretende é que a matriz curricular que norteia as disciplinas de sala aula, bem como as atividades ofertadas pelos macrocampos do PME, construam um currículo integrado, que ofereça ao aluno atividades que mesclem o conhecimento científico e o saber que ele possui. Para tornar possível essa revolução ou transformação, o coletivo precisa se fazer presente, ou seja, a comunidade escolar precisa estar empenhada nessa reorganização de tempo e espaços.

\section{CONSIDERAÇÕES FINAIS}

O Programa Mais Educação preconiza a oferta da educação integral destinada a crianças, adolescentes e jovens, por meio de atividades articuladas ao projeto de aprendizagem desenvolvido pela escola, através de uma portaria interministerial que reúne o empenho de outros ministérios para que se possa alcançar a educação pública de qualidade para todos, como almejava o Manifesto dos Pioneiros. Portanto, é imprescindível um debate ampliado sobre a compreensão de educação integral.

Educar integralmente é focar no desenvolvimento humano como horizonte que se realizará através de cada potencialidade de cada indivíduo, valorizando as capacidades e vinculando as inúmeras dimensões do sujeito - cognitiva, afetiva, ética, social, lúdica, estética, física, biológica.

A escola seria o espaço principal para isso, afinal, ela deveria ser promotora da igualdade de oportunidades e democratização ao acesso do saber. Todavia, há uma luta hegemônica nesse espaço; trata-se de um campo de disputa hegemônica, um espaço de luta e construção de democracia. Os processos educativos são subordinados ao interesse do capital. Logo, desenvolver o PME na escola, bem como ampliar o tempo por meio da escola de tempo integral, é um processo árduo e complexo. 
O contexto da educação integral tem em sua essência o objetivo de educar e proteger os alunos, de resgatar o processo de cuidar deles e de respeitá-los, não se tratando de desconfigurar a escola em sua função social. É necessário o estabelecimento do diálogo ampliado entre escolas e comunidades, o que permite tornar abrangente a dimensão das experiências escolares na vida dos alunos. Portanto, a escola será de suma relevância para o desenvolvimento do projeto de educação integral; não estando sozinha para a execução deste projeto, terá contribuição de outras políticas públicas, o que vai enriquecer a diversidade de vivências além da integração sólida de escola e comunidade.

Trata-se de reconhecer que a sociedade mudou e está cada vez mais complexa e extremamente desigual, e que a escola precisa ser mais do que um espaço que detém e repassa o saber pronto e acabado. A escola terá a incumbência de ser responsável pela socialização das gerações mais novas e ser determinante na preparação delas para o exercício da cidadania.

O PME tem a preocupação de ampliar a jornada escolar em sete horas diárias, o que resultaria na necessária modificação da rotina da escola. Ampliar o tempo é procurar fazer que o aluno permaneça mais tempo na escola, buscando garantir aprendizagens por meio de um novo modo de reorganizar os tempos, espaços e a logística em que se desenvolve o processo escolar, tendo também como preocupação a alimentação desse aluno.

Para a concretização disso no espaço escolar, há desafios a ser enfrentados, pois o programa chega a escolas onde o espaço físico é o primeiro obstáculo para seu desenvolvimento, além de professores que ainda precisam procurar superar o antigo modelo educacional de tempo reduzido. Por isso a formação continuada para professores e demais profissionais da escola é fundamental para o acolhimento desse programa na escola, bem como assegurar a permanência de alunos, ofertando assim uma educação integral de qualidade.

Logo, serão focalizados alguns desafios para o PME no espaço escolar, como a organização curricular visando à relação com o saber no espaço de aprendizagem; a elaboração do projeto político-pedagógico, prevendo o planejamento das atividades da escola envolvendo todos; a democratização da gestão, buscando potencializar a participação de órgãos como conselhos escolares, grêmios, associações e grupos constituídos na comunidade.

Eis a relevância da articulação deste Programa com outras políticas sociais, não reduzindo o PME a uma contribuição apenas na área educacional, e sim promovendo uma articulação na busca da melhoria da qualidade do ensino 
brasileiro que, através da educação integral, amplia tempos e espaços por meio do apoio das atividades socioeducativas.

Entendemos que para promover a educação integral o PME propõe a articulação de políticas sociais para favorecer ações socioeducativas, que serão materializadas por meio de orientações como o respeito à ampliação do tempo e espaço para desenvolver com maior qualidade as atividades do PME, de acordo com os componentes curriculares que permitam o diálogo entre os saberes que os alunos trazem e o conhecimento científico.

Ressaltamos que esses saberes concebem o valor cultural daquele local, logo consistem na carga cultural que os alunos trazem para a escola, sendo irrelevante sua condição social. Isso permitirá que os alunos possam aprender por meio das relações que surgem através da construção entre os saberes. 


\section{Programa Mais educação and the induction of full-time education: challenges for school curriculum}

Abstrac: This text focus on part of a master's degree dissertation that shows the precariousness affecting the quality of Brazilian public education. The public sector, thus, creates Plano de Desenvolvimento da Educação (PDE) [Project for Education Development] in 2007 composed of countless actions to improve such quality, focusing mainly on elementary education. Among the initiatives of this government program we have chosen Programa Mais Educação (PME) [More Education Program], which purpose is to resume fulltime education in Brazilian public schools, giving the students the opportunity of increasing the time they pass at school, the variety of spaces they frequent and other educational opportunities that will allow them to become full citizens. Therefore, we understand the importance the curriculum has in implanting the notion of full-time education and full-time school.

Keywords: Educational policy. Full-time education. Programa Mais Educação. Curriculum. 


\section{REFERÊNCIAS}

APPLE, Michael W. Ideologia e currículo. Porto Alegre: Artmed, 2006.

BRANCO, Verônica. A política de formação continuada de professores para a educação integral. In: MOLL, Jaqueline et al. (Orgs.). Caminhos da educação integral no Brasil: direito a outros tempos e espaços educativos. Porto Alegre: Penso, 2012.

BRASIL. Portaria Interministerial n. 17, de 24/04/2007. Institui o Programa Mais Educação, que visa fomentar a educação integral de crianças, adolescentes e jovens, por meio do apoio a atividades socioeducativas no contraturno escolar. Disponível em: 〈http://portal.mec.gov.br/index.php?option=com_co ntent\&view=article\&id=14887\&ltemid=817 . Acesso em: 10 out. 2010.

. Tendências para Educação Integral. 2007. Desenvolvida pelo Cenpec. Cita experiências de vários estados brasileiros. Disponível em: 〈http://www. direitosdacrianca.org.br/midiateca/publicacoes/tendencias-para-educacaointegralı. Acesso em: 22 jan. 2012.

Decreto Presidencial n. 7.083, de 27/01/2010. Dispõe sobre o Programa Mais Educação. Disponível em: 〈http://www.planalto.gov.br/ ccivil_03/_ato2007-2010/2010/decreto/d7083.htm». Acesso em: 10 out. 2010.

Manual de Educação Integral para obtenção de apoio financeiro através do Programa Dinheiro Direto na Escola - PDDE-MEC/2010. Brasília: MEC/Secad, 2010.

Manual Operacional de Educação Integral. Brasília: MEC/Secad, 2012.

. Manual Operacional de Educação Integral. Brasília: MEC/Secad, 2013.

CARLINI, Herb. A construção dos centros integrados em Americana e Santa Bárbara D’Oeste (SP). In: MOLL, Jaqueline et al. (Orgs.). Caminhos da educação integral no Brasil: direito a outros tempos e espaços educativos. Porto Alegre: Penso, 2012.

CAVALIERI, Ana Maria. Tempo de escola e qualidade da educação pública. Educação e Sociedade, Campinas, Cedes, v. 28, n. 100, 2007. . Educação integral e currículo integrado. In: MOLL, Jaqueline et al. 
(Orgs.). Caminhos da educação integral no Brasil: direito a outros tempos e espaços educativos. Porto Alegre: Penso, 2012.

COSTA, Natacha Gonçalves. Comunidades educativas: por uma educação para o desenvolvimento integral. In: MOLL, Jaqueline et al. (Orgs.). Caminhos da educação integral no Brasil: direito a outros tempos e espaços educativos. Porto Alegre: Penso, 2012.

GADOTTI, Moacir. Convocados, uma vez mais: ruptura, continuidade e desafios do PDE. São Paulo: Instituto Paulo Freire, 2008.

GAMBOA, Sílvio Sánchez; SANTOS, José Camilo dos. Pesquisa educacional: quantidade e qualidade. 7. ed. São Paulo: Cortez, 2009.

GODOY, Claudia M. O. Programa Mais Educação: mais do mesmo? Um estudo sobre a efetividade do Programa na rede pública municipal de São Luís do Maranhão. Brasília, 2012. Dissertação (Mestrado em Educação). Programa de Pós-Graduação da Universidade Católica de Brasília. 2012. Disponível em: 〈http://repositorio.ucb.br/jspui/bitstream/10869/892/1/Claudia\%20 Marcia\%20de\%200liveira\%20Godoy.pdf〉. Acesso em: 12 jun. 2012.

LAKATOS, Eva Maria; MARCONI, Marina de Andrade. Técnicas de pesquisa. In: LAKATOS, E. M.; MARCONI, M. A. Fundamentos de metodologia científica. 3. ed. São Paulo: Atlas, 1991.

LOMONACO, Beatriz Penteado; SILVA, Letícia Araújo Moreira da. Percursos da educação integral em busca da qualidade e da equidade. São Paulo: Cenpec: Fundação Itaú Social - Unicef, 2013.

MENEZES, Raquel. A importância do capital cultural de Bourdieu. Educação pública Cecierj, n. 13, jan. 2009. Disponível em: «http://www.educacaopublica. rj.gov.br/biblioteca/educacao/0204.html. Acesso em: 9 ago. 2012.

MOLL, Jaqueline. A política de educação integral no Brasil: Mais Educação. Colóquio Educação Integral. São Paulo: Cenpec, 2010.

- A agenda da educação integral: compromissos para sua consolidação como política pública. In: MOLL, Jaqueline et al. (Orgs.). Caminhos da educação integral no Brasil: direito a outros tempos e espaços educativos. Porto Alegre: Penso, 2012.

PINHEIRO, Lucineide; RODRIGUES, Rosa Luciana Pereira. A experiência de rede municipal de ensino de Santarém (PA). In: MOLL, Jaqueline et al. (Orgs.). 
Caminhos da educação integral no Brasil: direito a outros tempos e espaços educativos. Porto Alegre: Penso, 2012.

SACRISTÁN, J. Gimeno. 0 currículo: uma reflexão sobre a prática. 3. ed. Porto Alegre: Artmed, 1998.

SANTOS, Áurea Andrezza Silva dos. A gestão pedagógica do Programa Mais Educação: um olhar a partir da experiência da Escola Teodora Bentes. Belém, 2013. Dissertação (Mestrado em Educação) - Instituto de Ciências da Educação, Programa de Pós-Graduação em Educação, Universidade Federal do Pará.

SEVERINO, Antônio Joaquim. Metodologia do trabalho científico. 23. ed. rev. e atual. São Paulo: Cortez, 2007.

RECEBIDO: Janeiro de 2014.

APROVADO: Fevereiro de 2014. 